\title{
Development of fatigue cracks from mechanically machined scratches on 2024-T351 aluminium alloy-Part II: finite element analysis and prediction method
}

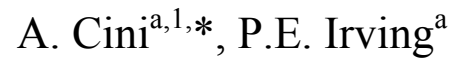 \\ a Damage Tolerance group, Department of Materials, Cranfield University, College Road, MK43 0AL, \\ Bedfordshire, UK \\ ${ }^{1}$ Present address: Institute for Advanced Manufacturing, Department of Mechanical, Materials and Manufacturing \\ Engineering, University of Nottingham, University Park, NG7 2RD, Nottingham, UK \\ * Corresponding author. Tel.: +44-(0)115-9514181 \\ E-mail address: andrea.cini@nottingham.ac.uk (A. Cini) \\ p.e.irving@cranfield.ac.uk (P.E. Irving)
}




\begin{abstract}
A prediction method to evaluate the effect of scratch geometry on fatigue life of aluminium structures containing scribe marks was developed on the basis of the experimental results described in Part I of this paper. Finite element calculations were performed on scribed samples to investigate the local stress around scribes. Elastic and elastic plastic stress and strain distributions at the scribe root were computed under monotonic and cyclic tensile and bending loads evaluating the driving force behind initiation and propagation from scribes. Scribe shape, size and cladding regulated stress and strain distributions in the neighbourhood of scribe roots. Fatigue life of tested scribed samples was divided into initiation life, defined as the cycles spent to develop a $50 \mu \mathrm{m}$ deep crack at scribe roots, and the remaining propagation life up to failure. Striation counting measurements were used to calculate propagation lives by integrating linear elastic $d a / d N$ vs. $\Delta K$ curves. Only up to a maximum of $38 \%$ of total fatigue life was spent to propagate an initial $50 \mu \mathrm{m}$ deep crack from scribe roots. The theory of critical distances was successfully applied to predict initiation lives of scribed samples from elastic stress distributions. A plastic correction was also suggested in the frame of the theory of critical distances, to correlate initiation lives of clad and unclad specimens.
\end{abstract}

Keywords: Notch fatigue; scratches; scribe marks; small cracks; notch stress; theory of critical distances

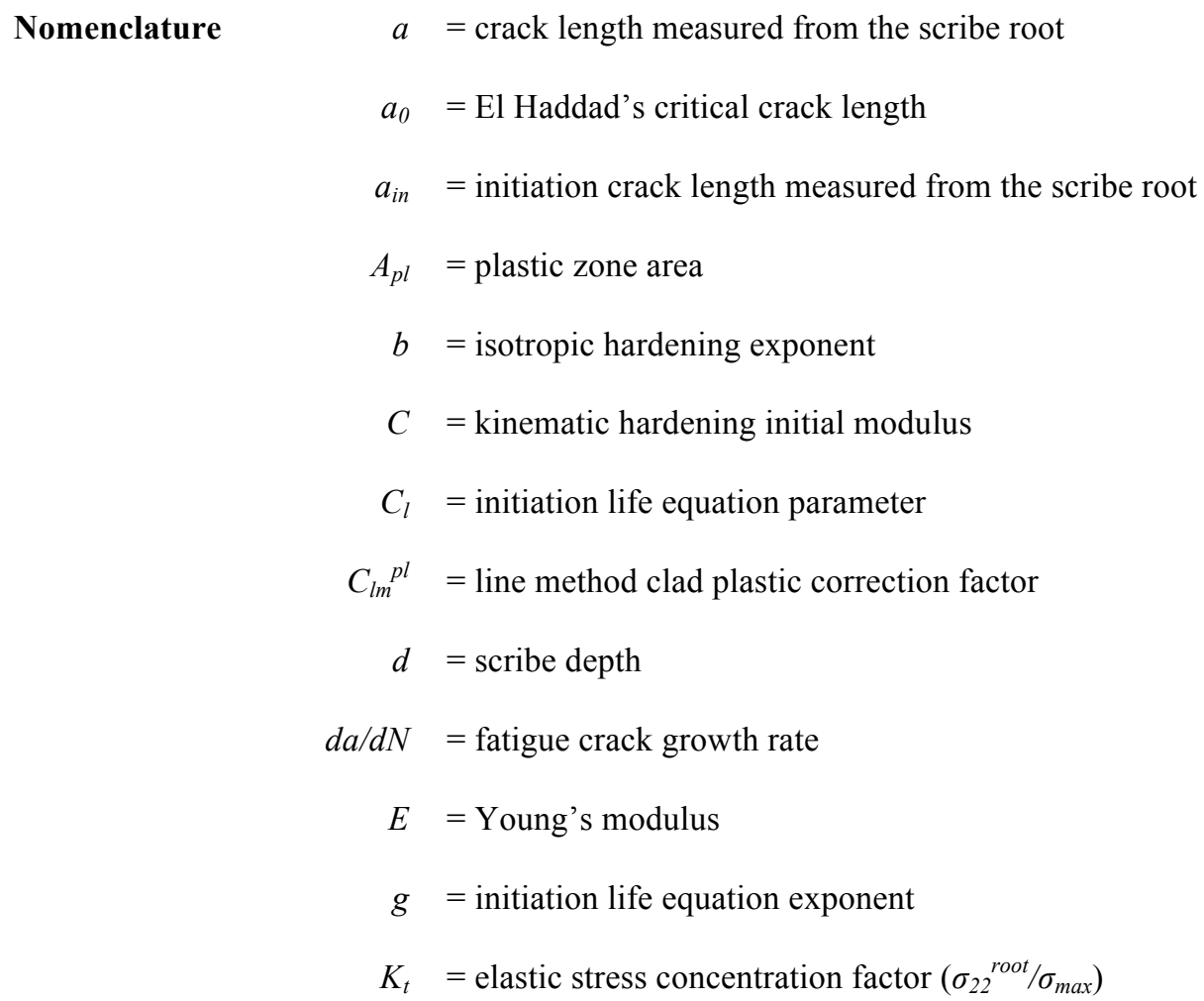




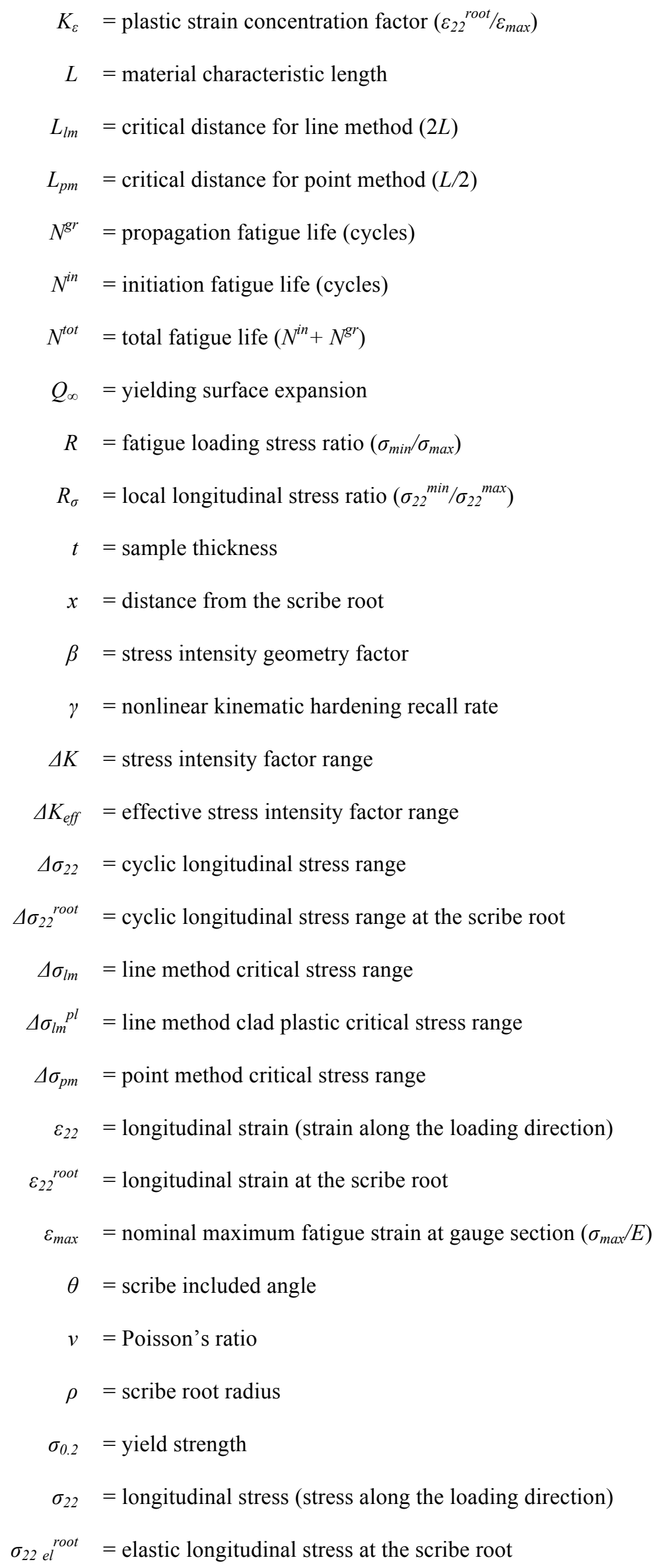




$$
\begin{aligned}
\sigma_{22}{ }^{\max } & =\text { maximum cyclic longitudinal stress at a given coordinate } x \\
\sigma_{22}{ }^{\text {min }} & =\text { minimum cyclic longitudinal stress at a given coordinate } x \\
\sigma_{22}{ }^{\text {root }} & =\text { longitudinal stress at the scribe root } \\
\sigma_{e l} & =\text { elastic limit } \\
\sigma_{\max } & =\text { nominal maximum fatigue stress at gauge section }(200 \mathrm{MPa})
\end{aligned}
$$

\section{Introduction}

Mechanically induced surface scratches less than $200 \mu \mathrm{m}$ deep, like scribe marks, despite their small size, are able to drastically reduce the fatigue life of aluminium components ${ }^{1}$. As described in Part I of this paper, scratches or scribes near mechanically fastened joints in fuselage panels can nucleate multiple cracks at their roots growing through the sheet thickness. An ad hoc prediction method is required to estimate residual service life of scribed structures and meet damage tolerance and durability requirements. Due to the rapid growth and difficult detection of cracks emanating from scribe marks, initiation fatigue life cannot be neglected ${ }^{2}$ or even durability analyses ${ }^{3}$. The entire crack development process has to be modelled from the geometry of the scribe and the properties of the alloy, making structural integrity assessment of scribed components an example of fatigue life prediction from notches.

Fatigue from conventional engineering notches of several millimetres size is traditionally characterised in the finitelife domain using the local strain approach ${ }^{4,5}$. This method is based on the hot spot approach according to which the fatigue process is defined exclusively by the local stress and strain range at the most highly stressed point ${ }^{6}$. As the numerical $^{6}$ and analytical ${ }^{7}$ maximum stress and strain ranges overestimate the fatigue notch effect, they are often replaced with effective values of the fatigue notch factor, $K_{f}$, in high-cycle fatigue ${ }^{8}$ and with plastic material properties in low-cycle fatigue regime $e^{6,9}$. The inability of the hot-spot approach to correctly predict fatigue initiation life, in particular from sharp notches, was therefore overcome by averaging notch root stress range over a specific length ${ }^{10,11}$. Average stress methods, sharing the definition of a characteristic material length parameter at the fatigue limit, have recently been rationalised and unified under the theory of critical distances ${ }^{12,13}$. This linear elastic approach has also been successfully extended to the medium-cycle fatigue regime ${ }^{14}$ and applied to V-notches the size of scribes ${ }^{15}$. Several researchers used the concept of notch elastic stress intensity factor ${ }^{16}$ as field parameter to estimate the fatigue life of

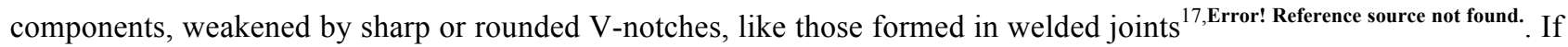
a small initial crack, the size of a particle or inclusion cluster, is assumed to exist at the root of engineering size notches ${ }^{19}$, fracture mechanics can be used to assess notch fatigue life. However short crack behaviour has to be considered for early crack propagation under the raised stress at the $\operatorname{root}^{19,20}$. 
For notches the size of scribe marks, conventional prediction methods, based on average stress approach, generally underestimate fatigue life reduction, as the length, over which stresses are averaged, is orders of magnitude longer that the region affected by the notch raised stress ${ }^{21}$. Small notches have proved to behave as material defects, in term of notch sensitivity ${ }^{21,22}$, and like voids and inclusions can be considered as initial small cracks ${ }^{23,24}$. In fact cracks can rapidly nucleate from sharp defects and it is their subsequent propagation across microstructural barriers ${ }^{25,26}$ or developing of crack closure ${ }^{27,28}$ which defines component fatigue lives. This crack growth approach is too conservative for scribe life prediction, as cycles to transform a defect into a growing crack could be a significant portion of the short life of scribed structures ${ }^{1}$. However a small-crack closure based model, where scratches were modelled as initial singleedge cracks, was able to accurately predict fatigue lives of scratched specimens ${ }^{29}$. Despite the revived attention of the aerospace structural engineers in fatigue life assessment of scratched structures, very few prediction models have been proposed for scribed components ${ }^{30-32}$.

This paper aims to develop a fatigue life prediction method able to accommodate the anomalous scribe behaviour, halfway between conventional engineering notches and small defects ${ }^{1}$. The relation between scribe cross section geometry and fatigue life of scribed samples was estimated to develop a simple conservative method for the residual service life assessment of scribed fuselage joints. On the basis of the experimental results described in Part I of this paper, a model for the life estimation of scribed components and assessment of damaging vs. non damaging scribes, was implemented. Finite element calculations were performed to determine local stress and strain fields at scribes. The effect of cladding and loading conditions on crack nucleation and propagation was determined. Scribe stress distributions and striation counting measurements were used to develop different prediction methods for initiation and propagation lives.

\section{Scribe stress calculation}

Elastic and elastic-plastic finite element stress analysis of scribes were performed using Abaqus. Local stress and strain distributions were calculated at scribes with five depths $(25 \mu \mathrm{m}, 50 \mu \mathrm{m}, 100 \mu \mathrm{m}, 150 \mu \mathrm{m}, 185 \mu \mathrm{m})$ and three root radii $(5 \mu \mathrm{m}, 25 \mu \mathrm{m}, 50 \mu \mathrm{m})$ with an included angle of $\theta=60^{\circ}{ }^{1}$. Elastic, monotonic elastic-plastic and cyclic plastic behaviour of clad and unclad scribed samples were modelled under tensile and bending loads. Due to sample geometries $^{1}$, the stress analysis was reduced to a two-dimensional plane strain problem ${ }^{33}$. Because of the large specimen width and the constraint exerted by the load-free scribe flanks, deformations along the scribe line were prevented. As plane strain conditions were fully developed just in the vicinity of scribe roots, fading away from stress concentration regions $^{33}$, two dimensional stress analyses approximate the mechanical behaviour of metal sheet structures. The Plane 
strain approximation was considered accurate enough to investigate the scribe geometry influence on local notch stress fields ${ }^{34}$. The plane strain assumption was representative only of the sample internal region neglecting the small scribe portions close to the specimen free edges, where transition to plane stress occurred.

Tension and bending samples were modelled as deformable two-dimensional plane strain sections (Fig. 1a). Taking advantage of mechanical symmetry half of the model was simulated. Consistent with the decay distance of the notch stress field, a rectangular portion of sample cross section, containing half of the scribe, as wide as the whole sample thickness and $2 \mathrm{~mm}$ high, was modelled ${ }^{34}$. Scribes were represented as rounded V-notches ${ }^{1}$. Cladding was modelled as a zone $80 \mu \mathrm{m}$ deep of different material, present at both sample surfaces and separated from the substrate by a sharp boundary (Fig. 1a). External longitudinal forces and the bending moments per unit of width, resolving into a maximum nominal stress of $\sigma_{\max }=200 \mathrm{MPa}$ at the section upper edge ${ }^{1}$, were applied respectively to tensile and bending models (Fig. 1a). Stress distributions at maximum fatigue test loads, were computed for monotonic elastic and elastic plastic analyses. The entire constant amplitude fatigue load history was simulated during cyclic elastic-plastic calculations. A structured mesh, consisting of quadrilateral 2D plane strain elements with aspect ratios smaller than 4 , refined around the scribe root, was defined in different models on the basis of mesh sensitivity analyses (Fig. 1b).

Fig. 1 Finite element model geometry (a) and unclad model mesh (b).

Cladding and substrate were modelled as homogeneous isotropic continua. Cladding was assumed to be Al 1080 with a purity of $99.8 \%$. The substrate was Al 2024 pre-stretched with $\varepsilon=2 \%$, in the T351 condition ${ }^{1}$. Table 1 lists mechanical properties of cladding and substrate. 2024 monotonic elastic-plastic stress-strain curve and its properties were experimentally measured along the long transverse direction, perpendicular to the scribe line, whereas those of Al 1080 were provided by Alcoa $^{34}$ (Fig. 2a). The elastic limit, $\sigma_{e l}$, and the yield strength, $\sigma_{0.2}$, (Table 1 ) were defined as the stresses corresponding to permanent plastic strains of $0.01 \%$ and $0.2 \%$ respectively. The time-independent incremental plasticity theory ${ }^{35}$, combined with the Von Mises yielding criterion and an isotropic hardening rule, based on the curves in Fig. 2a, was used to simulate the material monotonic inelastic behaviour. 2024 cyclic elastic-plastic behaviour was modelled on the basis of literature cyclic stress-strain test data ${ }^{34}$ (Fig. 2b). The same flow rule and yielding criterion used for monotonic analyses were applied to the cyclic analyses, but combined nonlinear kinematic plus isotropic hardening rule ${ }^{35}$ was chosen to characterise the material cyclic mechanical response (Fig. 2b). The kinematic hardening recall rate, $\gamma$, and initial modulus, $C$, as well as the of the yielding surface expansion, $Q_{\infty}$, and isotropic hardening exponent, $b$, were calibrated on the basis of experimental data ${ }^{34}$ (Fig. 2b). Cyclic elastic-plastic stress analyses were performed only on unclad scribed tension and bend samples. 
Fig. 2 Clad and substrate monotonic (a) and substrate cyclic (b) stress-strain curves.

Table 1 Cladding and substrate mechanical properties.

Elastic stress analyses were performed only on unclad specimens as the elastic properties of cladding and substrate are the same. ${ }^{34}$. Two dimensional plane strain quadrilateral 8-node second-order elements with reduced integration (CPE8R) were used for elastic analyses. Two dimensional continuum plane strain quadrilateral 4-node elements with full integration (CPE4) were used to model monotonic and cyclic elastic-plastic behaviour of both clad layer and substrate. In cyclic analyses, external tensile and bending loads were cycled in triangular constant amplitude fatigue loading sequences, with nominal maximum stress $\sigma_{\max }=200 \mathrm{MPa}$ and a stress ratio $R=0.1$, until stress-strain curves stabilised at the scribe root. 10 to 25 cycles were required to reach a stable cyclic behaviour ${ }^{34}$.

\subsection{Elastic stress analysis}

Fig. 3a shows the effect of scribe geometry on gross elastic stress concentration factor, $K_{t}$, plotting $K_{t}$ in tension against the ratio between scribe root radius, $\rho$, and depth, $d$. Scribe stress concentration values are listed in ${ }^{1} . K_{t}$ of rounded V-notches in semi-infinite plates calculated by Nowell et al. ${ }^{36}$ and the analytical formula suggested by Lazzarin et al. ${ }^{37}$ are shown in Fig. $3 \mathrm{a}$ as well. $K_{t}$ values of scribes with different geometry were correlated on a unique trend line by $\rho / d$ (Fig. 3a). The good agreement between these $K_{t}$ values and those from Nowell ${ }^{36}$ and Lazzarin ${ }^{37}$ (Fig. 3a) showed the weak influence of finite thickness on samples with scribe depth $d /$ thickness $t$ ratios $<1 / 10$. Kt values of scribe roots in bending showed similar but slightly smaller values of $\mathrm{Kt}^{1}$.

Fig. $3 \mathrm{~b}$ shows the longitudinal elastic stress, $\sigma_{22}$, distributions along the notch bisectors under tensile and bending loads, normalised with respect to their maximum values ${\sigma_{22}}^{\text {root }}$. plotted against distance from the scribe root normalised by the root radius, $x / \rho$. As the scribe bisector coincides with the plane of fatigue crack growth, $\sigma_{22}$ distributions are responsible for crack opening and propagation. These are also maximum principal stresses ${ }^{34}$. Normalised stress distributions overlapped near the root, following the trend predicted by the analytical stress solution of Filippi et al. ${ }^{38}$ for rounded V-notches (Fig. 3b). Scribes with a given geometry showed the same size region of enhanced stress in tension and bending (Fig. 3b). Longitudinal stresses near the root were uniquely defined by the maximum stress at the scribe root, i.e. $K_{t}$, and by the root radius ${ }^{38}$. The elastic $K_{t}$,(Fig. 3a), defined the influence of scribe shape on local stress, whereas $\rho$ introduced the effect of notch size on local stress gradients ${ }^{38}$. Scribe $\rho / d$ and the root radius, regulated the extent of the enhanced stress region (Fig. 3b). 
Fig. 3 Effect of the scribe geometry on elastic stress concentration factor under tensile load (a) and on normalised longitudinal elastic stress distributions along the scribe bisector (b); scribe geometry effect on plastic strain concentration factor under tensile load (c) and on monotonic elastic-plastic normalised longitudinal strain distributions along the scribe bisector $(\mathrm{d})$ in clad and unclad samples.

\subsection{Monotonic elastic-plastic stress analysis}

Fig. $3 \mathrm{c}$ shows the plastic strain concentration factor at the scribe root $\left(K_{\varepsilon}=\varepsilon_{22}{ }^{\text {root }} / \varepsilon_{\text {max }}\right)$ in clad and unclad tension samples as function of the notch aspect ratio, $\rho / d$. As for the elastic analyses, $\rho / d$ correlated the elastic-plastic $K_{\varepsilon}$ of unclad samples on a unique curve. Scribes with their roots in the substrate of clad specimens showed strain concentration factors up to $13 \%$ lower than in unclad samples, maintaining the same correlation with $\rho / d$ (Fig. $3 \mathrm{c}$ ). When scribe roots were within the cladding (Fig. 3c), $K_{\varepsilon}$ values were from 1.3 to 3.5 times higher than in unclad samples. There was a similar effect in bending ${ }^{34}$.

Normalised longitudinal elastic-plastic strain, $\varepsilon_{22}$, distributions along the scribe bisector are shown in Fig. $3 \mathrm{~d}$. plotted against normalised distance $x / \rho$. Strain distributions in clad and unclad samples almost overlapped close to the scribe (Fig. 3d). Normalised strain differences up to $15 \%$ in that superposition area were caused by different plastic zone sizes at the scribe root breaking mechanical similitude (Fig. 4a) ${ }^{34}$. Both clad and unclad samples showed the same overlapping trend. (Fig. 3d). The only effect of cladding was therefore to reduce or increase the strain magnitude depending on whether the scribe root was into the substrate or the cladding. Neglecting the effect of the plastic zone, near scribe elastic-plastic strain distributions were, approximately defined by the cladding and by scribe aspect ratio $\rho / d$, and notch root radius $\rho$. This last determined strain gradients.

Fig. 4a shows the monotonic plastic zone developed at scribe depths greater than clad layer thickness in clad and unclad tension samples. Halves of the complete distribution of plastic zone boundaries are shown in coordinates normalised with respect to the scribe root radius. Plastic zone shape in clad and unclad samples is regulated by $\rho / d$, passing from nearly semi-elliptical to a lobed contour for $\rho / d<0.135$ (Fig. 4a).

The effect of cladding on monotonic plastic zone size is shown in Fig. $4 \mathrm{~b}$ where the plastic zone area, $A_{p l}$, normalised with respect to the square of the scribe root radius, is plotted against $\rho / d$ for clad and unclad tension samples. Normalised plastic zone areas at the roots of every scribe in unclad samples and of those deeper than the clad layer in clad specimens followed two similar trend lines (Fig. 4b). For a given $\rho / d, A_{p l}$ was a quadratic function of the root radius. Neglecting the small variations caused by sample finite thickness, monotonic plastic zones developed in unclad or in the substrate of clad samples were uniquely regulated by $\rho / d$, and by $\rho$. The similitude of local mechanical conditions at scribe roots, observed for pure elastic analyses, was therefore maintained in elastic-plastic analysis ${ }^{34}$. 
Cladding reduced the normalised plastic zone area of scribes with their root inside the substrate by $13-18 \%$ compared to those of unclad samples (Fig. 4b). Scribes with $\rho / d \geq 2$, such as ones 25 um deep with 50 um root radius, did not develop a plastic zone at their root in substrate alloy. Correlation with $\rho / d$ was lost for scribes with their root roots in the cladding as they showed $A_{p l} / \rho^{2}$ values from 28 to 163 times larger than the corresponding unclad data (Fig. 4b). Bending samples showed a similar trend to that of tension ones ${ }^{34}$.

Fig. 4 Monotonic plastic zone shape (a) and normalised area (b) at the root and normalised elastic-plastic longitudinal stress distributions along the bisector of scribes in clad and unclad tension samples (c).

Fig. 4c shows a comparison between analytical elastic ${ }^{38}$ and numerical elastic-plastic normalised longitudinal stress distributions, $\sigma_{22}$. Longitudinal stresses were normalised with respect to the maximum elastic stress at the root, $\sigma_{22}$ el ${ }^{\text {root }}$, and plotted against normalised distance, $x / \rho$. The stress redistribution shifted the elastic portion of elastic-plastic $\sigma_{22}$ toward values of $x / \rho$ (Fig. 4c), making the scribe behave as it had a bigger root radius ${ }^{35}$. The presence of cladding reduced the $\sigma_{22}$ stress near scribe roots in the substrate by $5 \%$ compared to that of unclad distributions (Fig. $4 \mathrm{c}$ ). Scribe roots within the cladding had stresses at their roots between 2.6 and 3.3 times smaller than in unclad specimens. Distributions, showing discontinuities at the cladding/substrate interface, were elastic into the substrate as no scribe plastic zones spread into the substrate ${ }^{34}$. Whether scribe roots were inside the clad layer or the substrate the presence of cladding reduced the scribe effectiveness as stress raiser lowering or shifting $\sigma_{22}$ distributions.

\subsection{Cyclic elastic-plastic stress analysis}

Fig. 5a shows the stable longitudinal cyclic stress-strain behaviour at the scribe root under tensile load. Scribes with $\rho / d>0.2$ had no cyclic plastic deformation at the root as their $\sigma_{22}-\varepsilon_{22}$ cycles were elastic (Fig. 5a). The hysteresis loops of scribes with $\rho / d \leq 0.2$ had zero mean stress due to the mean stress relaxation caused by stable plastic deformations ${ }^{35}$ (Fig. 5a). $\rho / d$ regulated stress and strain ranges of the loops. the smaller the $\rho / d$, the larger the loop area, that is the plastic energy per unit of area dissipated at the scribe root every cycle ${ }^{35}$. Fig. $5 \mathrm{~b}$ shows the comparison between monotonic and stabilised cyclic plastic zone areas. Plastic zone areas, $A_{p l}$, normalised with respect to $\rho^{2}$ are plotted against scribe aspect ratios. Normalised cyclic plastic zone areas were correlated by the scribe aspect ratio, showing local mechanical similitude also under fatigue loads (Fig. 5b). Scribes with the same $\rho / d$, developed cyclic plastic zones with similar shapes and areas proportional to $\rho^{2}$, the square of the scribe size ${ }^{34}$. Cyclic plastic zone areas of tension and bending samples were respectively 10-20 and 15-40 times smaller than the corresponding monotonic ones. Bending 
loading reduced monotonic and cyclic plastic zones at scribe roots on average by respectively $33 \%$ and $57 \%$ compared to tension ones (Fig. 5b).

Fig. 5 Stabilised longitudinal stress-strain cycles at scribe roots under fatigue tensile loading (a) and comparison between cyclic and monotonic plastic zone areas under tensile and bending loads (b); effect of the scribe geometry on longitudinal elastic-plastic stress range (c) and on local cyclic longitudinal stress ratio (d) distributions along scribe bisectors in tension samples

Elastic-plastic stress range, $\Delta \sigma_{22}$, distributions along scribe bisectors of tension samples, normalised with respect their values at the root, $\Delta \sigma_{22}{ }^{\text {root }}$, are plotted in Fig. 5c against $x / \rho$. Stress range distributions of scribe with $\rho / d \leq 0.2$ showed trends similar to those of monotonic $\sigma_{22}$ ones, reaching their maxima close to the plastic zone boundary (Fig. $5 \mathrm{c})$. The nonlinearity introduced by the plastic behaviour made the stress range at the root, $\Delta \sigma_{22}{ }^{\text {root }}$ and $\rho$ unable to uniquely define other stress ranges nearby (Fig. 5c). Normalised stress distributions of scribes with $\rho / d>0.2$, showed elastic behaviour. However the inelastic deformation history, produced plasticity-induced residual stresses as well as in scribes with elastic distributions ${ }^{35}$. Residual stresses, altered the local, $R_{\sigma}$ ratio, of the stress cycles, defined as the ratio between the local minimum and maximum cyclic stress $\sigma_{22}$, after material response stabilisation $\left(R_{\sigma}=\sigma_{22}{ }^{\text {min }} / \sigma_{22}{ }^{\text {max }}\right)$.

Fig. $5 \mathrm{~d}$ shows the local stress ratios of the $\Delta \sigma_{22}$ stabilised distributions of Fig. $5 \mathrm{c}$ as function of the normalised distance from the scribe root. Due to lack of monotonic plasticity and thus of plasticity-induced residual stresses, $25 \mu \mathrm{m}$ deep $50 \mu \mathrm{m}$ root radius scribe showed $R_{\sigma}$ equal to the nominal cyclic load ratio $R=0.1$ at any distance from the notch root. Scribes with $\rho / d \leq 0.2$, showed stable elastic-plastic cyclic response and developed compressive residual stresses at their roots, causing $R_{\sigma}=-1$ inside the cyclic plastic zone (Fig. 5d). Such mean stress relaxation caused almost straincontrolled conditions inside cyclic plastic zones ${ }^{35}$. Negative stress ratios higher than $R_{\sigma}=-1$ were observed at the root of scribes with $\rho / d>0.2$ which developed elastic $\Delta \sigma_{22}$ distributions along their bisectors. The material at the scribe root which experienced monotonic plastic deformation during loading, , was subjected to compressive plastic-induced residual stresses, $R_{\sigma}<0.1$, whereas the elastic surrounding had tensile residual stresses, $R_{\sigma}>0.1$ (Fig. $5 \mathrm{~d}$ ).

\section{Fatigue life prediction}

\subsection{Crack propagation life}

Total fatigue life was divided into initiation life, $N^{\text {in }}$, defined as the number of cycles needed to nucleate and develop cracks, and propagation life, $N^{g r}$, consisting of remaining crack growth up to failure. Since cracks developed 
transgranular stage II growth by $50-100 \mu \mathrm{m}$ from the scribe $\operatorname{root}^{1}$, an initiation crack length of $a_{i n}=50 \mu \mathrm{m}$ was defined. For samples which in ${ }^{1}$ showed crack fronts of multiple cracks, only the main cracks were assumed to grow, neglecting development of secondary cracks ${ }^{19}$. Coalescence of cracks, was considered to occur within the initiation life. Crack shapes were assumed to remain constant throughout propagation life and the same as those measured experimentally on fracture fronts ${ }^{34}$. Growth rates obtained by striation counting in tension and bending ${ }^{1}$ were correlated to linear elastic $\Delta K$, calculated at crack lengths through the sample thickness. As scribe geometry affected crack growth rates, only by altering sample ligaments ${ }^{1}$, stress intensity factor ranges were computed from standard linear elastic fracture mechanics solutions ${ }^{39,40}$ adding the scribe depth, $d$, to crack lengths to give total crack lengths. $\Delta K$ equations for throughthickness $^{39}$, corner quarter-elliptic or surface semi-elliptical ${ }^{40}$ cracks were applied according to main crack shapes on sample fracture fronts ${ }^{34}$. Fig. 6a shows a comparison between crack growth rates in scribed samples, plotted against the calculated $\Delta K$ values and those of long cracks in 2024-T351 growing in the long transverse direction at $R=0.1{ }^{41}$. Growth rates of short cracks, propagating from circular holes in 2024-T3 aluminium under constant amplitude loading with $R=0^{19}$, are plotted in Fig. 6a as well. Crack growth rates from different scribes in tension and bending in clad and unclad samples followed a common trend. Cracks nucleated at scribe roots showed non-conservative short crack behaviour, growing faster than long ones with the same $\Delta K$ for the entire propagation stage (Fig. 6a). Scribed sample data merged into long crack curve only near the critical crack length for fast fracture. The multiple crack nucleation at scribe roots, and their coalescence during early growth ${ }^{1}$ were thought to accelerate short crack propagation in the range of $4<\Delta K<20 \mathrm{MPa} \cdot \mathrm{m}^{1 / 2}$ compared to that at the root of conventional engineering notches ${ }^{42}$ (Fig. 6a).

Fig. 6 Crack growth rates in scribed samples plotted against the stress intensity factor range (a) and propagation life of scribed samples under tensile load

A trend line, defining a power function of $\Delta K$, was obtained by fitting the growth rate data of Fig. $6 \mathrm{a}$ and was used as $d a / d N$ vs. $\Delta K$ curve of crack propagating from scribe roots. Propagation lives of every scribed specimen was estimated by integrating such curve from $a_{i n}$ to the critical crack length for unstable fracture ${ }^{34}$. Striation counting data were also used to calculate crack growth life in pristine specimens from an initiation crack length of $a_{i n}=50 \mu \mathrm{m}^{34}$. Crack growth in the clad layer was not included in the propagation life. Fig. $6 \mathrm{~b}$ shows the number of cycles of crack propagation in scribed tension samples, as percentages of total fatigue lives, $N^{\text {tot }}$. plotted against scribe $K_{t}$. Although growth rate was insensitive to scribe geometry ${ }^{1}$ (Fig. 6a), it affected the percentage of total life spent to propagate initial cracks at the scribe root, the length of $50 \mu \mathrm{m}$, to sample failure (Fig. 6b). The growth of a $50 \mu \mathrm{m}$ deep crack from scribe roots occupied from $3.6 \%$ to $38 \%$ of total fatigue cycles, reaching thelargest fraction for the sharpest $185 \mu \mathrm{m}$ deep, 5 
$\mu \mathrm{m}$ root radius, scribes. Percentage growth lives in clad samples were on average $25 \%$ smaller than in unclad ones. Propagation cycles occupied nearly the same total life fractions under tensile and bending loads ${ }^{34}$.

\subsection{Crack initiation life}

Initiation lives at scribe roots, obtained subtracting from total fatigue cycles those spent for propagation, were predicted by applying the theory of critical distances, reformulated for finite life regime ${ }^{14}$, to scribed samples. This theory, relating the damage of a fatigue fracture process zone to the stress acting on $\mathrm{it}^{12}$, is generally used to predict total life of notched components. The small scale of fracture process zone at the scribe root, compared to the sample size justifies, the use of the theory of critical distances only as initiation life prediction method, following the approach described in ${ }^{15}$. Due to the lack of experimental S-N curves of scribed and pristine samples, the alternative method suggested by Yamashita ${ }^{15}$ was used to determine the critical distance from low-cycle to high-cycle fatigue life regimes by comparing $\Delta \sigma_{22}$ distributions of scribes with different root radii. Three pairs of clad and unclad tension samples, showing similar initiation lives, were selected to cover fatigue regimes from $10^{4}$ to $10^{5}$ cycles (Table 2). Initiation lives of additional samples, with $185 \mu \mathrm{m}$ deep $5 \mu \mathrm{m}$ root radius scribes, tested under constant amplitude tensile load at $\sigma_{\max }=160 \mathrm{MPa}$ and $\sigma_{\max }=100 \mathrm{MPa}^{34}$, were used for the critical distance determination. According to point or line method, $L_{p m}$ and $L_{l m}$ were defined as the distances from scribe root which ensured equal critical stress ranges for samples with comparable initiation lives ${ }^{15}$. Critical stress ranges were calculated from linear elastic $\Delta \sigma_{22}$ distributions along scribe bisectors. Table 2 shows $L_{p m}$ and $L_{l m}$, computed at different initiation lives in clad and unclad tension samples. As for small V-notches in titanium specimens ${ }^{15}$, critical distances of clad and unclad samples were substantially independent of initiation life. The average values, $L_{p m}=7.10 \mu \mathrm{m}$ and $L_{l m}=38.11 \mu \mathrm{m}$, were used as constant critical distances through the whole finite life range (Table 2). Due to the equivalence of their $\Delta \sigma_{22}$ elastic distributions, critical distances were identical in clad and unclad samples.

Table 2 Critical distance calibration under tensile load.

The critical distance stress ranges $\Delta \sigma_{p m}$ and $\Delta \sigma_{l m}$ of point and line methods, i.e. the elastic $\Delta \sigma_{22}$ at a distance equal to $L_{p m}$ and the average of $\Delta \sigma_{22}$ over a distance $L_{l m}$ from the scribe $\operatorname{root}^{12}$, were calculated for each scribed tension sample and used to correlate initiation fatigue lives. Fig. $7 \mathrm{a}$ and $\mathrm{b}$ show initiation fatigue lives of unclad and clad tension samples, including those tested under different maximum stresses, as function of line method critical stress range, $\Delta \sigma_{l m}$. The critical distance stress range was able to correlate almost all the initiation lives of scribed unclad and unclad samples, on unique trend lines representing power functions of $\Delta \sigma_{l m}$ (Fig. 7). $N^{\text {in }}$ from scribes under tensile fatigue load at $R=0.1$ was, therefore, estimated using the following expression: 


$$
N^{i n}=C_{l} \Delta \sigma_{l m}^{g}
$$

where the best fit least square parameter $C_{l}$ and exponent $g$ are listed in Table 3. Prediction method based on eq. (1) was capable of estimating initiation lives within an error of about $\pm 25 \%$ apart from $5 \mu \mathrm{m}$ root radius scribes, $25 \mu \mathrm{m}$ and 50 $\mu \mathrm{m}$ deep in unclad samples, and $50 \mu \mathrm{m}$ deep in clad ones, for which non conservative predictions were obtained (Fig. 7). As $N^{\text {in }}$ reached the value of pristine specimens (characterised by $\Delta \sigma_{l m}=180 \mathrm{MPa}$ ) at a stress range close to the ones of $25 \mu \mathrm{m}$ deep scribes, any additional $\Delta \sigma_{l m}$ reduction did not alter the initiation life (Fig. 7). The critical stress, defining the threshold of fatigue life sensitivity to scribes, was respectively $\Delta \sigma_{l m}=249.5 \mathrm{MPa}$ and $\Delta \sigma_{l m}=270.4$ for unclad and clad samples, under tensile fatigue load at $\sigma_{\max }=200 \mathrm{MPa}$ and $R=0.1$. Eq. (1) was not able to predict the asymptotic behaviour of $N^{\text {in }}$ but that could be ascribed to a miscalculation of critical stresses for pristine samples. Crack nucleation in unscribed specimens, in fact, occurred at large intermetallic inclusions $25-50 \mu \mathrm{m}^{34}$, which, acting as stress raisers, could produce stresses comparable to those of undamaging $25 \mu \mathrm{m}$ deep scribes with $25 \mu \mathrm{m}$ and $50 \mu \mathrm{m}$ root radii ${ }^{1}$.

Table 3 Equation parameters to predict initiation lives of scribed tension samples by critical distance line method.

Fig. 7 Relation between initiation lives and line method critical stress ranges in scribed unclad (a) and clad (b) tension samples.

\section{Discussion}

\subsection{Effect of scribe size}

Crack development from scribe marks is a notch fatigue problem, where the stress concentrators are several centimetres long and few tens of microns deep. The two different scales, place long superficial scratches in an intermediate position between conventional engineering notches, several millimetres in size ${ }^{19}$ and small defects the size of the material characteristic microstructural lengths ${ }^{23,24,43}$. Due to their small depths, scribes show, as microstructural defects, stress raising regions and notch root plastic zones the size of few grain diameters. The small scale of local stress concentration areas makes crack nucleation and early propagation from notches sensitive to material microstructure. Short crack growth generally occurs along crystallographic planes and microstructural barriers, like grain boundaries, can slow down or even arrest propagating cracks ${ }^{25,26}$. Such microstructurally short crack behaviour is not observed at the root of engineering size notches where short crack growth is mainly ascribed to crack closure evolution and plastic deformation regulated by the local stress distribution ${ }^{19,20,27,28}$. However for long scribes, where many possible nucleation sites exist at the notch $\operatorname{root}^{1}$, the microstructure variability is averaged over many grains and crack nucleation and early 
propagation are less affected by the material microstructure ${ }^{43}$. Nucleation of multiple cracks and their coalescence during propagation mitigates the crack growth restraint of unfavourable grain orientation and microstructural barriers, increasing the detrimental effect of scribes on component fatigue lives. Such a mechanism makes aluminium structures more sensitive to scribes ${ }^{1}$ than to small damage or defects, the size of scribe depths ${ }^{26,44}$. The two different scales of scribes invalidates the application of fatigue life prediction methods specific for both engineering size notches ${ }^{16-19}$ and small defects ${ }^{23-26}$.

The small scale of scribe stress concentration areas also invalidates the assumption of homogenous and isotropic continuum medium ${ }^{33}$, at the basis of continuum mechanics stress and strain analysis. As long as the scale of mechanical problems is orders of magnitude larger than the characteristic microstructural length, like for conventional engineering notches, the assumption of homogeneity can be effectively applied, since mechanical properties and responses of local material elements are the average of those heterogeneous of several randomly oriented grains ${ }^{33}$. For scribes, developing stress raising regions 20-120 $\mu \mathrm{m}$ deep, that is from 1 to 6 grain diameters deep, (Fig. 4c and Fig. 5c), microstructural heterogeneity and local discontinuous stress fields at different locations along the scribe $\operatorname{root}^{45}$, cannot be averaged out. Computationally expensive stochastic models, based on crystal plasticity ${ }^{45}$, might have been used to characterise the mechanical response of scribes by including the effect of microstructure. However surface scribe lengths, corroborate the application of continuum mechanics to characterise the mechanical behaviour along the entire scribe root in a global way, by averaging out local microstructural responses of many grains. Crack nucleation and early propagation are sensitive to local stress conditions inside single grains, but, as multiple nucleation and crack coalescence occurred along the scribe root $^{1}$, the continuum characterisation of average homogeneous stress and strain fields at roots was considered more appropriate to describe scribe effects on crack development.

\subsection{Crack growth at scribe roots}

Finite element elastic crack growth analyses were performed to estimate the effect of local scribe stress field on early crack propagation for which no striation spacing data were available. Growth of 2D through-width cracks along the scribe bisector under fatigue tensile load was simulated from an initial length $0.4 \mu \mathrm{m}$ by progressively releasing nodes at their tips. Linear elastic stress intensity factors of cracks propagating from scribe roots were derived from $J$ integrals computed around tips at every length increment ${ }^{34}$. Fig. $8 \mathrm{a}$ shows the comparison between the stress intensity geometry factors, $\beta$, of through-width cracks growing from the root of scribes and from the tip of initial edge cracks, as deep as scribes, under tensile load. $\beta$ factors were calculated adding the scribe depth and the initial edge crack length $a_{l}$, to that of cracks, $a$, i.e. measuring crack depths from the sample edge ${ }^{34}$. The driving force reduction caused by the 
presence of scribes into the crack wake with respect to that of conventional edge cracks was therefore assessed. Geometry factors were plotted in Fig. 8a against the crack length, $a$, measured from the scribe root or from the initial edge crack tip. Due to their non-zero root radius ${ }^{38}, \beta$ factors of cracks growing from scribes were smaller than the corresponding values of edge cracks in proximity of the root (Fig. 8a). Driving force reduction near the scribe root was regulated only by the root radius, increasing as $\rho$ increased. The smaller the notch root radius and the scribe depth, the shorter the distance from the root, $a$, at which edge and scribe crack $\beta$ curves merged (Fig. 8a). This distance, defining the size of the crack growth region affected by the local scribe stress field, reached a maximum of $a=50 \mu \mathrm{m}$, for $185 \mu \mathrm{m}$ deep, $50 \mu \mathrm{m}$ root radius scribes (Fig. 8a). Scribe influence was therefore exerted only on the microstructure sensitive stage I-like crack propagation, leaving unaffected the growth rate measured by striation counting ${ }^{1}$, as proved by the common trend line in Fig. 6a. It is worth noticing that $\beta$ factors were calculated performing linear elastic analyses, thus neglecting the effect of scribe plasticity and multiple crack interaction ${ }^{34}$. Scribe plasticity generally increases the crack driving force available at the root, reducing the size of the growth region affected by the local scribe stress field.

Fig. 8 Scribe geometry effect on stress intensity factor of cracks emanating from scribe roots under tensile load (a) and comparison between experimental growth rate from scribes and short crack analytical corrections (b).

Fig. $8 \mathrm{~b}$ shows the comparison between experimental crack growth rates in scribed specimens and the effective propagation rate curve of 2024-T3 aluminium alloy obtained under closure-free constant amplitude loading at $R=0.7^{27}$. Growth curves, calculated applying El Haddad's short crack length correction ${ }^{46}$ and the Dugdale's plastic zone correction ${ }^{47}$ to two-dimensional edge cracks propagating from an initiation length of $a_{i n}=50 \mu \mathrm{m}$ in pristine samples ${ }^{34}$, are shown as well in Fig. 8b. A critical crack length of $a_{0}=71.79 \mu \mathrm{m}$ was calculated for El Haddad's length correction ${ }^{34}$, from growth threshold of $\Delta K_{t h}=2.58 \mathrm{MPa} \cdot \mathrm{m}^{1 / 2}{ }^{41}$, and a fatigue limit value of $\Delta \sigma_{e}=172 \mathrm{MPa}^{22}$. For $\Delta K<8.13 \mathrm{MPa} \cdot \mathrm{m}^{1 / 2}$ scribed samples showed crack growth rates higher than those predicted by the $\Delta K_{\text {eff }}$ curve (Fig. 8b), clashing with the assumption of plastic-induced crack closure model, according to which the closure-free effective crack growth curve represents the growth rate upper limit $^{27}$. Even the El Haddad short crack model and the Dugdale's plastic zone corrections were not able to predict crack propagation from scribes, underestimating the experimental growth rates (Fig. 8b). As conventional approaches failed to characterise growth rates of cracks propagating from scribes, plastic induced closure, tip plastic zone, and intrinsic crack length were not considered to be alone the main cause of anomalous crack growth rates from scribes ${ }^{34}$.

\subsection{The theory of critical distances applied to scribe marks}


The theory of critical distances, able to characterise the initiation life of scribe samples, assumes material behaviour as purely elastic, neglecting plasticity ${ }^{12}$. The correct application of critical distances requires small-scale yielding conditions at notch roots, satisfied when the cyclic plastic zone is small compared to the critical distance $L$. Unclad samples showed cyclic plastic zone extended up to $4.36 \mu \mathrm{m}$ that is about $12 \%$ of the line method critical distance $L_{l m}{ }^{34}$. Stress ranges $\Delta \sigma_{l m}$ were calculated at scribe roots, averaging the cyclic elastic-plastic $\Delta \sigma_{22}$ distributions along the bisector over the distance $L_{l m}=38.11 \mu \mathrm{m}$ to analyse the effect of plasticity on critical distance predictions. Table 4 shows the comparison between the critical stress ranges of unclad tension specimens computed using the elastic and elasticplastic cyclic $\Delta \sigma_{22}$ distributions and their percentage difference, $e$. Elastic and elastic-plastic critical stress ranges were almost identical, showing a maximum difference modulus of $|e|=0.5 \%$ for $185 \mu \mathrm{m}$ deep, $5 \mu \mathrm{m}$ root radius scribes (Table 4). Small-scale yielding conditions were therefore fulfilled at the root of scribes fatigued under constant amplitude tensile loading with $\sigma_{\max }=200 \mathrm{MPa}$ and the theory of critical distances could be accurately applied to predict sample initiation lives. Due to the short portion of fatigue life (up to $38 \%$ of total fatigue life) spent to propagate an initial 50 $\mu \mathrm{m}$ deep crack up to sample failure (Fig. 6b), the theory of critical distances could be used to adequately predict total fatigue lives of scribed samples ${ }^{34}$.

Table 4 Critical distance calibration under tensile load.

Cladding increased initiation lives at the root of scribes on average by $70 \%$ compared to those of unclad samples (Fig. 7). The soft clad layer altered elastic plastic longitudinal stress and strain distributions along scribe bisectors producing, for scribes with their roots into the substrate, stresses and strains respectively $13 \%$ and $5 \%$ lower than those in unclad samples (Fig. 3c and Fig. 4c). Due to its linear elastic nature ${ }^{12}$, the theory of critical distances was not able to take into account these variations. In fact critical stress ranges at scribe roots were identical in clad and unclad samples for which two distinct, nearly parallel, $N^{\text {in }}$ prediction curves were developed (Fig. 7). To correlate initiation lives of clad and unclad samples on a unique prediction curve by including the effect of plasticity, plastic critical stress ranges, $\Delta \sigma_{l m}^{p l}$, were defined for clad samples as follows:

$$
\Delta \sigma_{l m}^{p l}=C_{l m}^{p l} \Delta \sigma_{l m}
$$

where:

$$
C_{l m}^{p l}=\frac{\left.\int_{0}^{L_{l m}} \varepsilon_{22} d x\right|_{\text {clad }}}{\left.\int_{0}^{L_{l m}} \varepsilon_{22} d x\right|_{\text {unclad }}}
$$


Critical stress ranges for the line method, $\Delta \sigma_{l m}$, of clad specimens were weighted by a plastic correction factor, $C^{p l}{ }_{l m}$. This, defined as the ratio between the averages over $L_{l m}$ of the monotonic elastic-plastic $\varepsilon_{22}$ distributions along the scribe bisector of clad and unclad samples (eq. (3)), estimates the strain field variations caused by cladding. Fig. 9 shows the initiation lives of unclad and clad samples as a function of elastic and plastic critical stress ranges respectively. The plastic correction factor was able to correlate initiation lives of clad and unclad samples on a unique curve for scribes with their root inside the substrate (Fig. 9). $N^{\text {in }}$ of specimens with scribes embedded into cladding, characterised by high plastic strain distributions (Fig. 3c), were up to 13 times those predicted by the unclad curve for the same critical stress (Fig. 9). The stress and strain reduction at the root of scribes, which were deeper than the clad layer, was therefore responsible for longer initiation lives than those of unclad samples, whereas for scribes with roots embedded in cladding the longer $N^{\text {in }}$ was thought to be due to crack growth obstruction exerted by the cladding/substrate interface ${ }^{48}$.

Fig. 9 Correlation between initiation lives of unclad and clad samples using a plastic correction factor to line method critical stress range.

The calculated critical distances for the line and point method, $L_{p m}=7.10 \mu \mathrm{m}$ and $L_{l m}=38.11 \mu \mathrm{m}$, could be related to the material grain size along the short transverse direction ${ }^{1}$, as $L_{l m}$ was about the length of two grain diameters along this direction, $2 d=40 \mu \mathrm{m}$, while $L_{p m}$ was slightly smaller than $d / 2=10 \mu \mathrm{m}$. Despite the theory of critical distances success in predicting initiation lives of scribe samples, physical evidence is still needed to rationalise the correlation between the elastic critical stress and fatigue crack initiation and early propagation from scribes ${ }^{12}$.

\section{Conclusions}

- Finite element analysis has shown monotonic and cyclic elastic-plastic stress and strain fields in the neighbourhood of scribes, as well as monotonic and cyclic plastic zones, were determined by the scribe shape and size. Due to mechanical similitude, scribes with the same shape but different size showed similar plastic zones and stress and strain distributions. Scribe shape and size univocally defined elastic stress distributions near the root, by determining respectively their magnitudes and gradients. For elastic-plastic stresses, the nonlinearity introduced by the plastic deformation prevented this univocal characterisation which however was approximatively maintained for elasticplastic strain distributions also in clad samples.

- The presence of surface cladding reduced the stress and strain distributions and the plastic zone size of scribes with their root within the substrate alloy by $5-18 \%$ compared to those of unclad samples, preserving anyway the correlation between scribe shape and size and the mechanical response in proximity of their roots. For scribes totally 
embedded into the cladding, the lack of mechanical similitude produced by the soft clad layer, made scribe geometry, expressed by the root radius and the aspect ratio, not the only factor defining stress and strain distributions.

- The propagation of an initial $50 \mu \mathrm{m}$ deep crack from scribe roots occupied from $4 \%$ up to $38 \%$ of total fatigue life of clad and unclad samples. The majority of life was spent in initiating and growing fatigue cracks up to $50 \mu \mathrm{m}$. Propagation lives in clad samples were on average $25 \%-34 \%$ smaller than in unclad ones. Growth rates of cracks propagating from scribes under tensile and bending loads, which showed short crack behaviour, were not characterised by plastic-induced crack closure, plastic zone or intrinsic crack length correction propagation models. Scribes influenced the crack growth up to a depth of $50 \mu \mathrm{m}$ from their roots.

- Despite the lack of physical basis, the theory of critical distances was capable of characterising the initiation fatigue life of clad and unclad scribed samples, defined as the number of cycles to generate a crack, $50 \mu \mathrm{m}$ deep from the scribe root. The critical distances seemed to be related to the material grain structure along the crack growth direction. Small-scale yielding conditions at the scribe root corroborated the use of liner elastic stress distribution to calculate critical stresses. A plastic correction factor, applied to critical stresses of clad samples was able correlate initiation live of clad and unclad specimens only for scribes deeper than cladding.

- The developed prediction method and in particular the theory of critical distances, provide a simple conservative methodology to estimate the residual service life of scribed fuselage joints from the measurement of scribe geometry.

\section{Acknowledgments}

This research activity was founded by Airbus. The support of Dr. Domenico Furfari From Airbus in providing the research group with samples as well of Mr. Ben Hopper from Cranfield University in scribing specimens is gratefully acknowledged.

\section{References}

1. Cini, A., Irving, P. E. (2016) Development of fatigue cracks from mechanically machined scratches on 2024-T351 aluminium alloy-Part I: experimentation and fractographic analysis. Fatigue Fract. Eng. Mater. Struct., x(x), x-x.

2. Gallagher, J. P., Giessler, F. J., Berens, A. P., Engle, Jr. R. M. (1984) USAF damage tolerant design handbook: guidelines for the analysis and design of damage tolerant aircraft structures. AFWAL-TR-82-3073. 
3. Manning, S. D., Yang, J. N. (1984) USAF durability design handbook: guidelines for the analysis and design of aircraft structures. AFWAL-TR-83-3027.

4. Manson, S. S., Hirschberg, M. H. (1967) Low cycle fatigue of notched specimens by consideration of crack initiation and propagation. NASA Technical Note D-3146.

5. Troshchenko, V. T. (2010) Fatigue of metals under nonuniform stressed state. Part 1. Stresses state assessment methods and results of investigation. Strength Mater., 42(2), 129-143.

6. Bentachfine, S., Pluvinage, G., Gilgert, J., Azari, Z., Bouami, D. (1999) Notch effect in low cycle fatigue. Int. J. Fatigue, 21, 421-430.

7. Neuber, H. (1961) Theory of stress concentration for shear-strained prismatic bodies with arbitrary nonlinear stress-strain law. J. Appl. Mech., 28, 544-550.

8. Dowling, N. E. (1979) Fatigue at notches and the local strain fracture mechanics approaches. ASTM STP, 677, pp. 247-273.

9. Glinka, G. (1985) Energy density approach to calculation of inelastic stress and strain near notches and cracks Eng. Fract. Mech., 22(508), 485-508.

10. Lazzarin, P., Tovo, R., Meneghetti, G. (1997) Fatigue crack initiation and propagation phases near notches in metal with low notch sensitivity. Int. J. Fatigue, 19(8-9), 647-657.

11. Livieri, P., Tovo, R. (2004) Fatigue limit evaluation of notches, small cracks and defects: an engineering approach. Fatigue Fract. Eng. Mater. Struct., 27, 1037-1049.

12. Taylor, D. (2007) The theory of critical distances. A new perspective in fracture mechanics. Elsevier: Amsterdam.

13. Taylor, D. (2008) The theory of critical distances. Eng. Fract. Mech., 75, 1696-1705.

14. Susmel, L., Taylor, D. (2007) A novel formulation of the theory of critical distances to estimate lifetime of notched components in the medium-cycle fatigue regime. Fatigue Fract. Eng. Mater. Struct., 30, 567-581.

15. Yamashita, Y., Ueda, Y., Kuroki, H., Shinozaki, M. (2010) Fatigue life prediction of small notched Ti-6Al-4V specimens using critical distance. Eng. Fract. Mech., 77, 1439-1453.

16. Lazzarin, P., Tovo, R. (1996) A unified approach to the evaluation of lineal elastic stress fields in the neighbourhood of cracks and notches. Int. J. Fracture, 78, 3-19.

17. Lazzarin, P. and Livieri, P. (2001) Notch stress intensity factors and fatigue strength of aluminium and steel welded joints. Int. J. Fatigue, 23, 225-232.

18. Verreman, Y., Limodin, N. (2008) Fatigue notch factor and short crack propagation. Eng. Fract. Mech., 75, 13201335. 
19. Newman, J. C. Jr., Edwards, P. R. et al. (1988) Short-crack growth behaviour in an aluminium alloy-An AGARD cooperative test programme. AGARD report 732.

20. Edwards, P. R., Newman, J. C. Jr. et al. (1990) Short-crack growth behaviour in various aircraft materials. AGARD report 767.

21. Atzori, B., Lazzarin, P., Meneghetti, G. (2003) Fracture mechanics and notch sensitivity. Fatigue Fract. Eng. Mater. Struct., 26, 257-267.

22. Atzori, B., Lazzarin, P., Meneghetti, G. (2005) A unified treatment of the mode I fatigue limit of components containing notches or defects. Int. J. Fracture, 133, 61-87.

23. Murakami, Y., Endo, M. (1980) Effect of small defects on fatigue strength of metals. Int. J. Fatigue, 2(1), 23-30.

24. Murakami, Y., Endo, M. (1994) Effects of defects, inclusions and inhomogeneities on fatigue strength. Int. J. Fatigue, 16(3), 163-182.

25. Navarro, A., de los Rios, E. R. (1988) Short and long fatigue crack growth: A unified model. Philos. Mag. A, 57(1), 15-36.

26. Vallellano, C., Mariscal, M. R., Navarro, A., Domínguez, J. (2005) A Micromechanical approach to fatigue in small notches. Fatigue Fract. Eng. Mater. Struct., 28, 1035-1045.

27. Newman, J. C. Jr., Phillips, E. P., Swain, M. H. (1997) Fatigue-life prediction methodology using small crack theory. NASA Technical Memorandum 1103079.

28. McEvily, A. J., Endo, M., Yamashita, K., Ishihara, S., Matsunaga, H. (2008) Fatigue notch sensitivity and the notch size effect. Int. J. Fatigue, 30, 2087-2093.

29. Everett, R. A. Jr., Newman, J. C. Jr., Phillips, E. P. (2002) The effect of Machining-like scratch on the fatigue life of 4340 steel. J. Am. Helicopter Soc., 47(3), 151-155.

30. Nader, N. A. (1993) The effect of scratches on fatigue life and fatigue crack growth of Al 2024-T3 clad. Ph.D. thesis, Wichita State University, US.

31. Talia, M., Talia, J. E. (1997) Crack propagation modeling for surface generated scratches in Al 2024-T3 clad alloy. J. Mech. Behav. Mater., 8(2), 117-139.

32. Das, G., Kosai, M., Miller, M. (2007) Development of a method for damage tolerance analysis for scribe marks adjacent to fuselage longitudinal and circumferential splices. In: International Committee on Aeronautical Fatigue (ICAF) meeting, Napoli, Italy, 14-18 May 2007.

33. Timoshenko, S. P., Goodier, J. N. (1970) Theory of elasticity. 3rd ed., McGraw-Hill: Singapore.

34. Cini, A. (2012) Scribe marks at fuselage joins: initiation and propagation of fatigue cracks from mechanical defects in aluminium alloys. Ph.D. thesis, Cranfield University, UK. 
35. Lemaitre, J., Chaboche, J.-L. (1994) Mechanics of solid materials. 1st ed., Cambridge University Press: UK.

36. Nowell, D., Dini, D., Duò, P. (2003) Stress analysis of V-notches with and without cracks with application to foreign object damage. J. Strain Anal. Eng., 38(5), 429-441.

37. Lazzarin, P., Filippi, S. (2006) A generalised stress intensity factor to be applied to rounded V-shaped notches. Int. J. Solids Struct., 43, 2461-2478.

38. Filippi, S., Lazzarin, P., Tovo, R. (2002) Developments of some explicit formulas useful to describe elastic stress fields ahead of notches in plates. Int. J. Solids Struct., 43, 4543-4565.

39. Rooke, D. P., Cartwright, D. J. (1974) Compendium of Stress Intensity Factors. Her Majesty's Stationery Office: London, UK.

40. Newman, J. C. Jr., Raju, I. S. (1984) Stress-intensity factor equations for cracks in three-dimensional finite bodies subjected to tension and bending loads. NASA Technical Memorandum 85793.

41. Cunningham, S., Fawaz, S., Harter, J. A., Litvinov, A., Newman, D., Wu, H. R. (2004) AFGROW Material Database version 4.0009e.12, downloadable computer software, United States Air Force, 2004.

42. Murakami, Y. (2002) Metal fatigue: effects of small defects and non-metallic inclusions. Elsevier Science Ltd.: Oxford, UK.

43. Taylor, D. (1986) Fatigue short cracks: the limitations of fracture mechanics. In: The behaviour of short fatigue cracks (edited by Miller, K. J., de los Rios, E. R.). EGF Pub. 1 Mechanical Engineering Publications: London, 1986, pp. 479-490.

44. DuQuesnay, D. L., Topper, T. H., Yu, M. T. (1986) The effect of notch radius on the fatigue notch factor and the propagation of short cracks. In: In: The behaviour of short fatigue cracks (edited by Miller, K. J., de los Rios, E. R.). EGF Pub. 1 Mechanical Engineering Publications: London, 1986, pp. 323-335.

45. Hill, R. (1966) Generalised constitutive relations for increment deformation of metals crystals by multislip. $J$. Mech. Phys. Solids, 14, 95-102.

46. El Haddad, M. H., Dowling, N. E., Topper, T. H., Smith, K. N. (1979) Fatigue crack propagation of short crack. J. Eng. Mater-T ASME, 101(1), 42-46.

47. Dugdale, D. S. (1960) Yielding in steel sheets containing slits. J. Mechan. Phys. Solids, 8, 100-104.

48. Schijve, J., Jacobs, F. A., Tromp, P. J. (1976) The significance of cladding for fatigue of aluminium alloys in aircraft structures. NLR TR 76065 U. 


\section{Table 1}

\begin{tabular}{|c|c|c|c|c|c|c|c|c|c|}
\hline \multirow[b]{2}{*}{ Material } & \multicolumn{2}{|c|}{ Elasticity } & \multicolumn{3}{|c|}{ Monotonic plasticity } & \multicolumn{4}{|c|}{ Cyclic plasticity } \\
\hline & $\begin{array}{c}E \\
{[\mathrm{MPa}]}\end{array}$ & $v$ & $\begin{array}{c}\sigma_{e l} \\
{[\mathrm{MPa}]}\end{array}$ & $\begin{array}{c}\sigma_{0.2} \\
{[\mathrm{MPa}]}\end{array}$ & $\begin{array}{c}\sigma-\varepsilon \\
\text { curve }\end{array}$ & $\begin{array}{c}Q_{\infty} \\
{[\mathrm{MPa}]}\end{array}$ & $b$ & $\begin{array}{c}C \\
{[\mathrm{MPa}]}\end{array}$ & $\gamma$ \\
\hline Al 2024-T351 & 72000 & 0.33 & 350.4 & 360.0 & Fig. 2a & 75.8 & 4 & 6252 & 60 \\
\hline Al $1080(\varepsilon=2 \%)$ & 72000 & 0.33 & 130.0 & 132.3 & Fig. 2a & - & - & - & - \\
\hline
\end{tabular}


Table 2

\begin{tabular}{rrrrrrr}
\hline \multicolumn{2}{c}{$\begin{array}{c}N^{\text {in }} \\
\text { [cycles] }\end{array}$} & \multicolumn{2}{c}{ Compared samples } & \multicolumn{2}{c}{$\begin{array}{c}\text { Critical distance } \\
{[\mu \mathrm{m}]}\end{array}$} \\
\cline { 5 - 7 } \cline { 4 - 6 } Unclad & Clad & & & $L_{p m}$ & $L_{l m}$ \\
\hline 108277 & 160187 & $\mathrm{~T}-185-5(100 \mathrm{MPa})$ & $\mathrm{T}-50-50$ & 7.31 & 37.11 \\
23466 & 31571 & $\mathrm{~T}-185-5(160 \mathrm{MPa})$ & $\mathrm{T}-150-50$ & 7.06 & 38.71 \\
10811 & 16445 & $\mathrm{~T}-150-5$ & $\mathrm{~T}-185-50$ & 6.92 & 38.51 \\
\hline \multicolumn{2}{c}{ Average } & & & 7.10 & 38.11 \\
\hline
\end{tabular}


Table 3

\begin{tabular}{lcc}
\hline \multicolumn{1}{c}{ Material } & $C_{l}$ & $g$ \\
\hline A1 2024-T351 unclad & $6.875 \cdot 10^{14}$ & -3.905 \\
A1 2024-T351 clad & $1.614 \cdot 10^{15}$ & -3.959 \\
\hline
\end{tabular}




\section{Table 4}

\begin{tabular}{|c|c|c|c|}
\hline \multirow[t]{2}{*}{ Sample } & \multicolumn{2}{|r|}{$\begin{array}{c}\Delta \sigma_{l m} \\
{[\mathrm{MPa}]}\end{array}$} & \multirow[t]{2}{*}{$e[\%]$} \\
\hline & Elastic & Elastic-plastic & \\
\hline T-U-25-5 & 283.42 & 283.74 & 0.114 \\
\hline T-U-50-5 & 363.11 & 363.09 & -0.004 \\
\hline T-U-100-5 & 491.08 & 490.50 & -0.119 \\
\hline T-U-150-5 & 601.48 & 599.48 & -0.335 \\
\hline T-U-185-5 & 674.74 & 671.36 & -0.503 \\
\hline T-U-25-25 & 278.52 & 278.35 & -0.063 \\
\hline T-U-25-50 & 273.12 & 272.86 & -0.095 \\
\hline T-U-50-50 & 340.06 & 339.58 & -0.141 \\
\hline T-U-100-50 & 447.29 & 446.54 & -0.168 \\
\hline T-U-150-50 & 540.45 & 539.35 & -0.204 \\
\hline T-U-185-50 & 602.70 & 600.80 & -0.315 \\
\hline
\end{tabular}


Fig 1
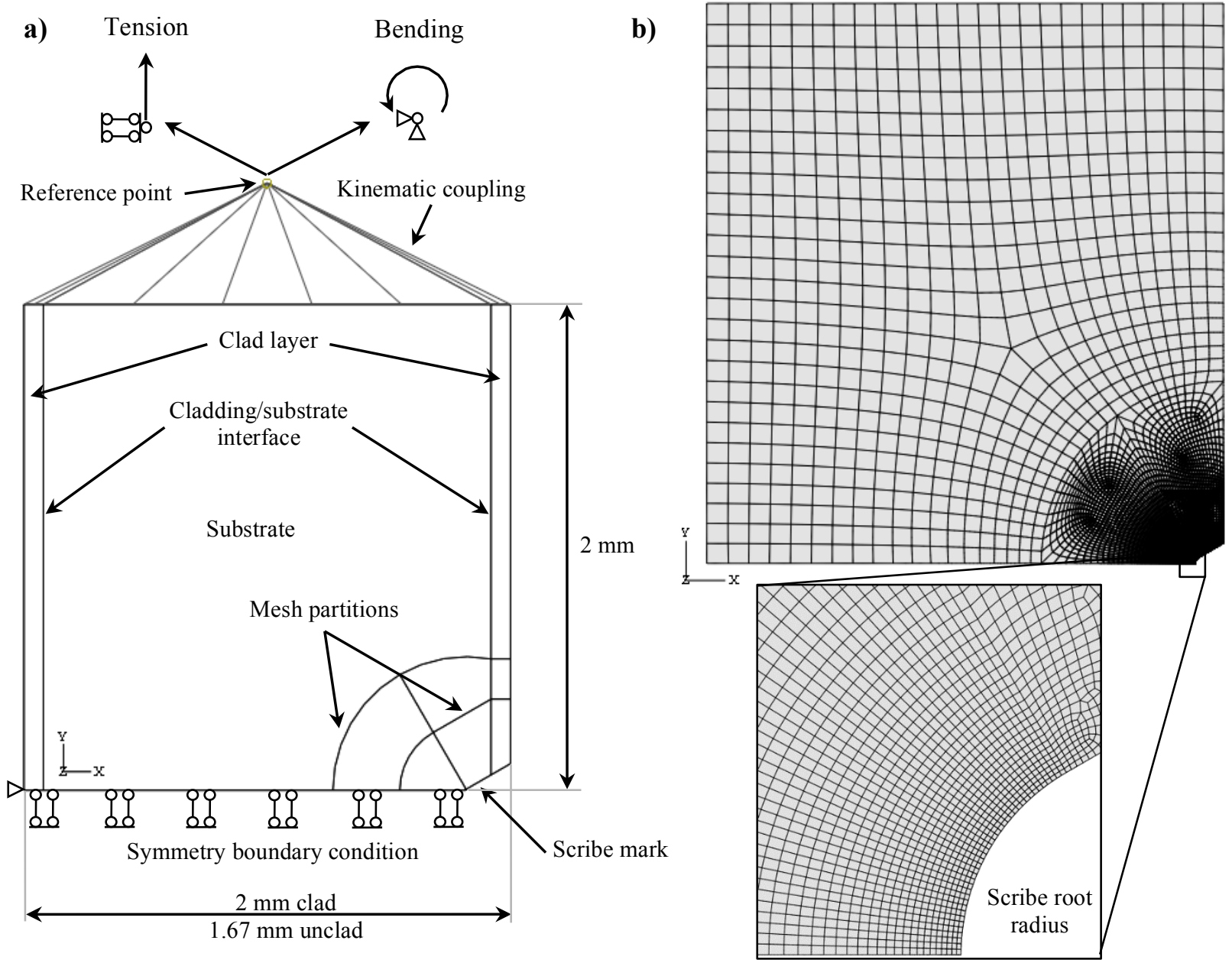
Fig 2
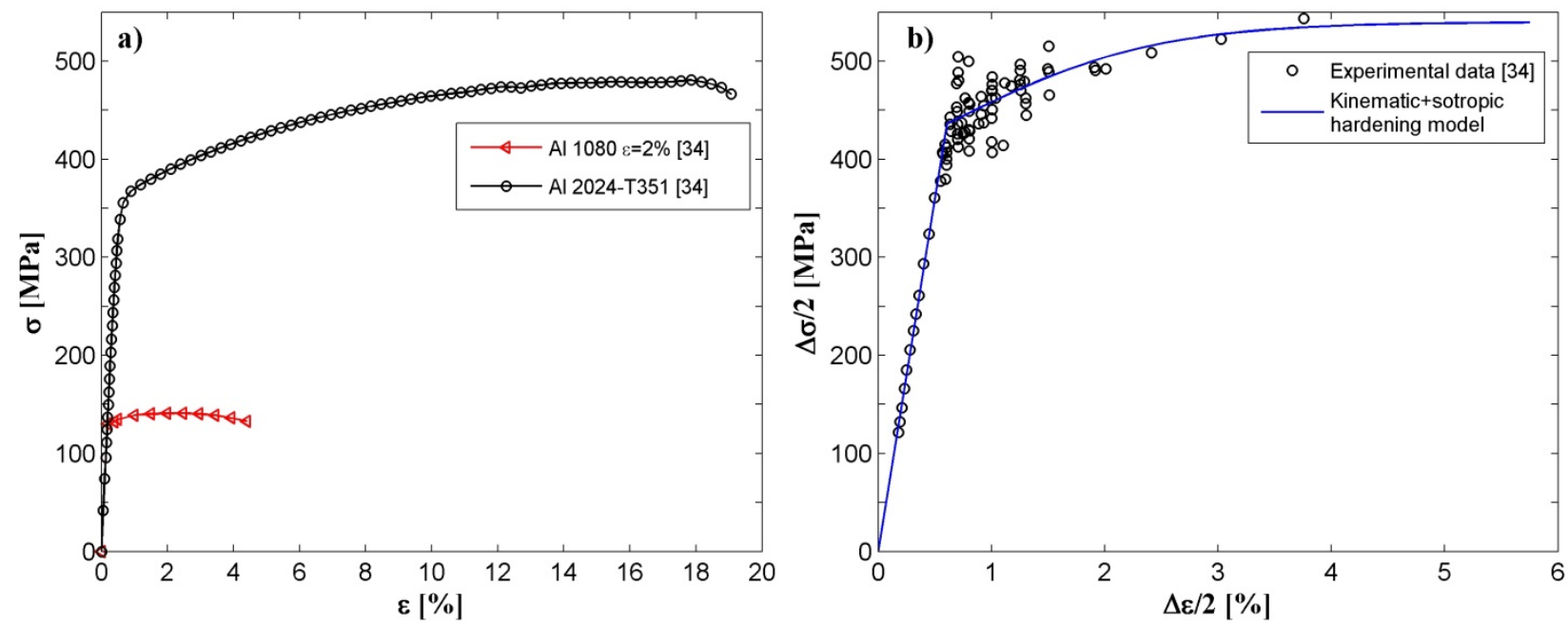
Fig 3
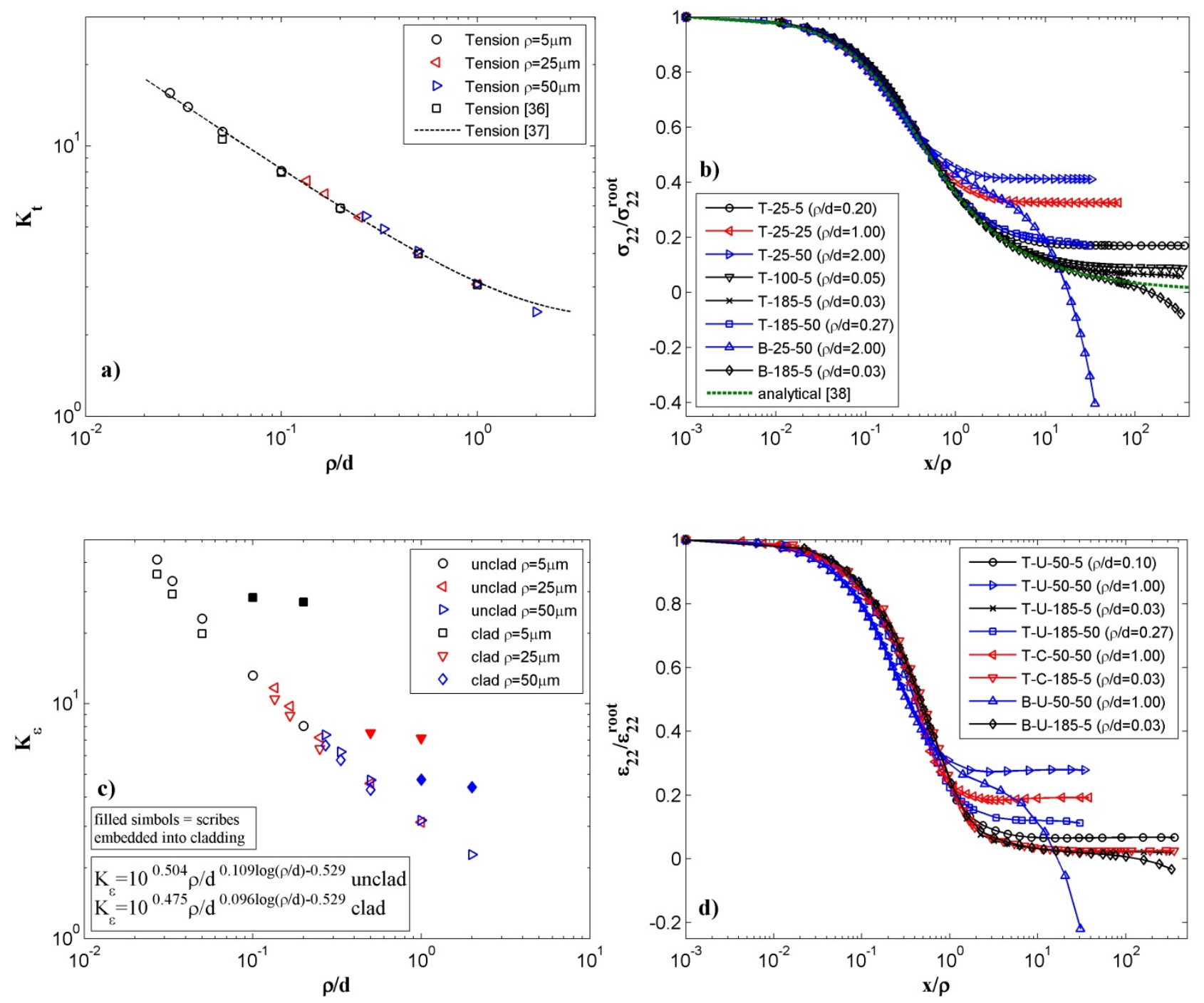
Fig 4
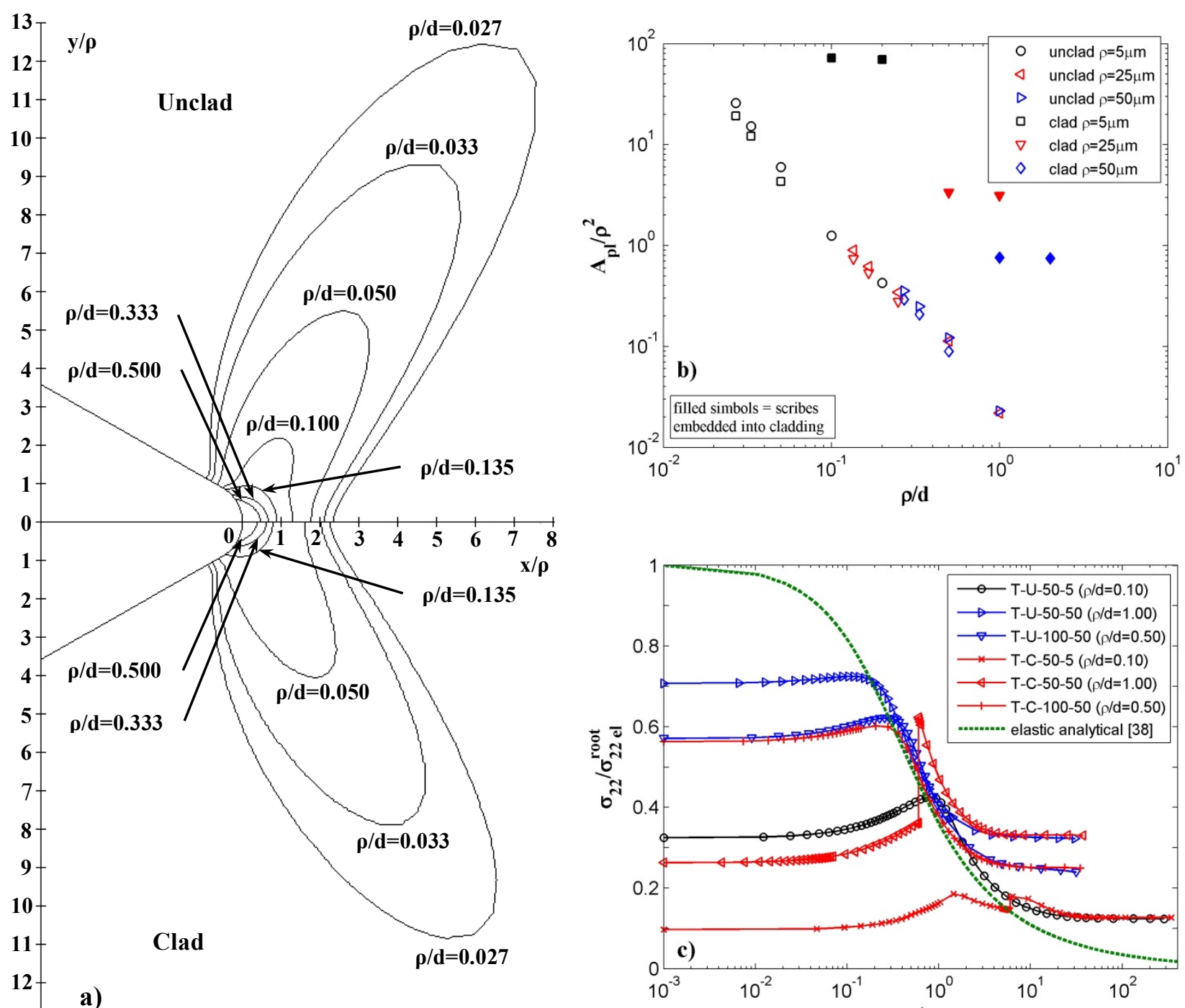

13

a)

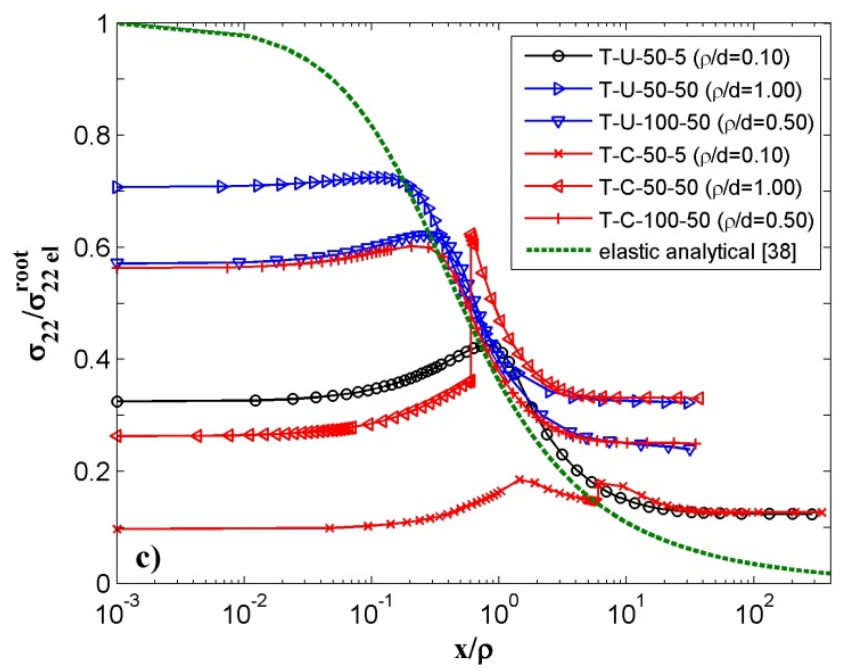


Fig 5
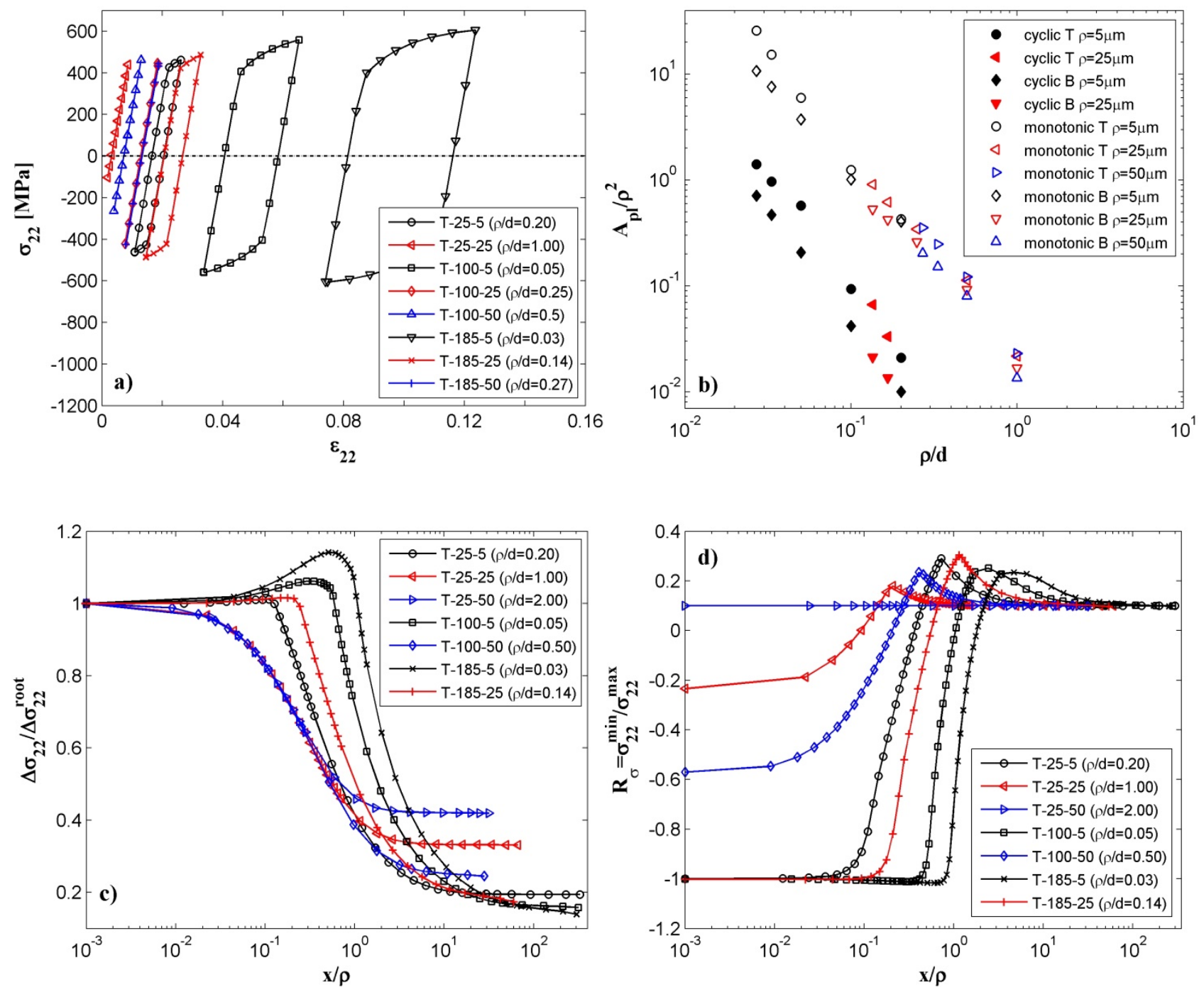
Fig 6
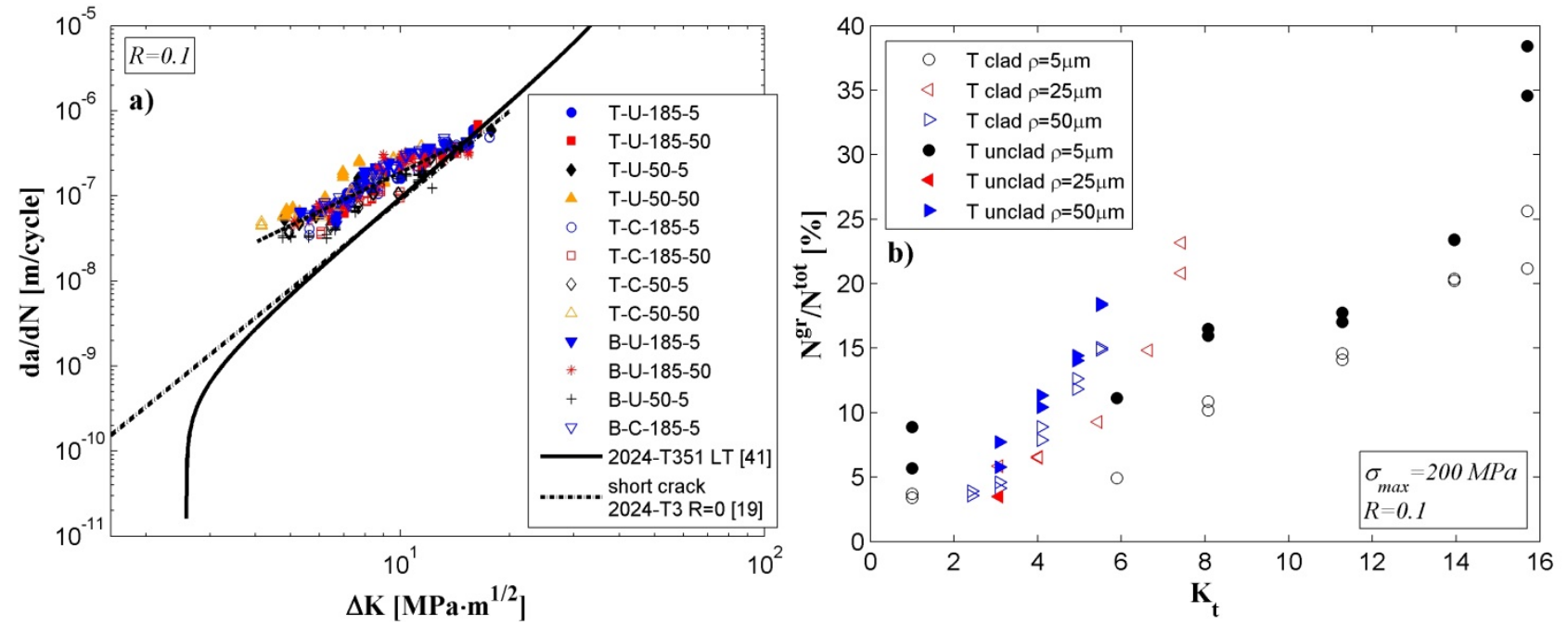
Fig 7
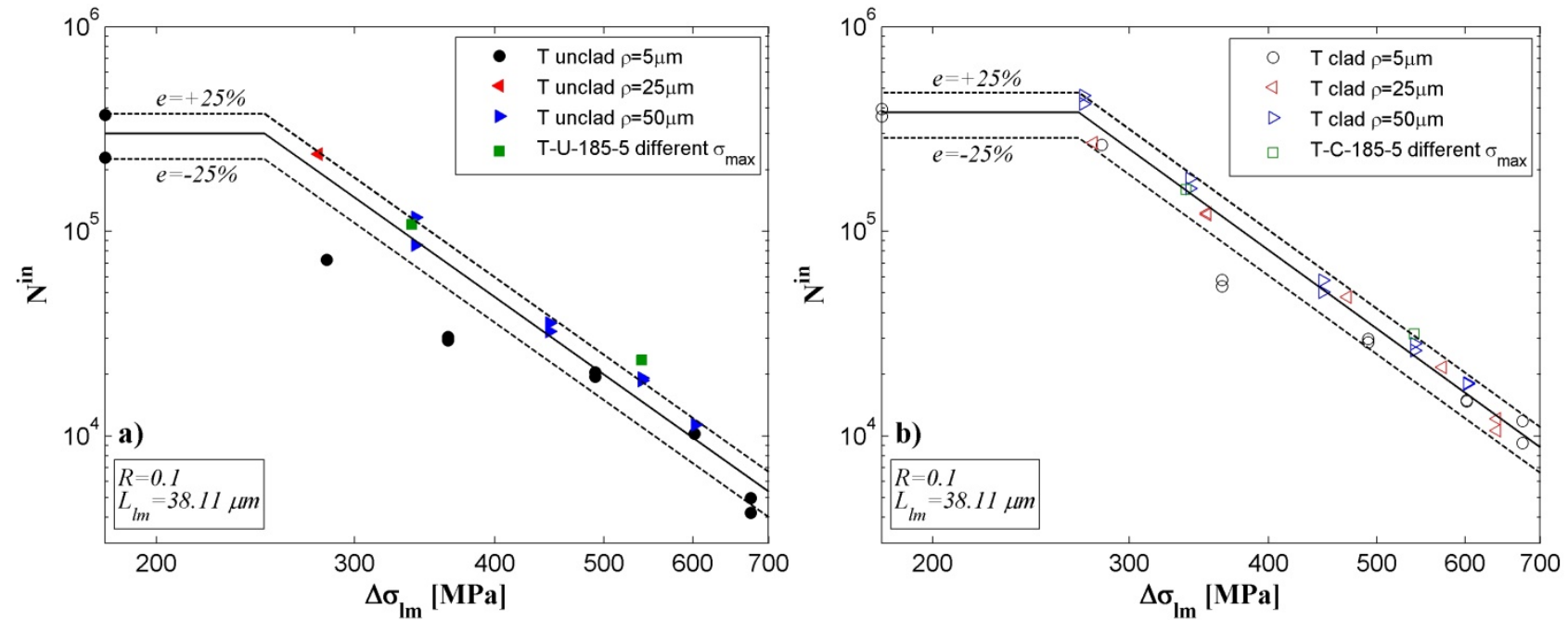
Fig 8
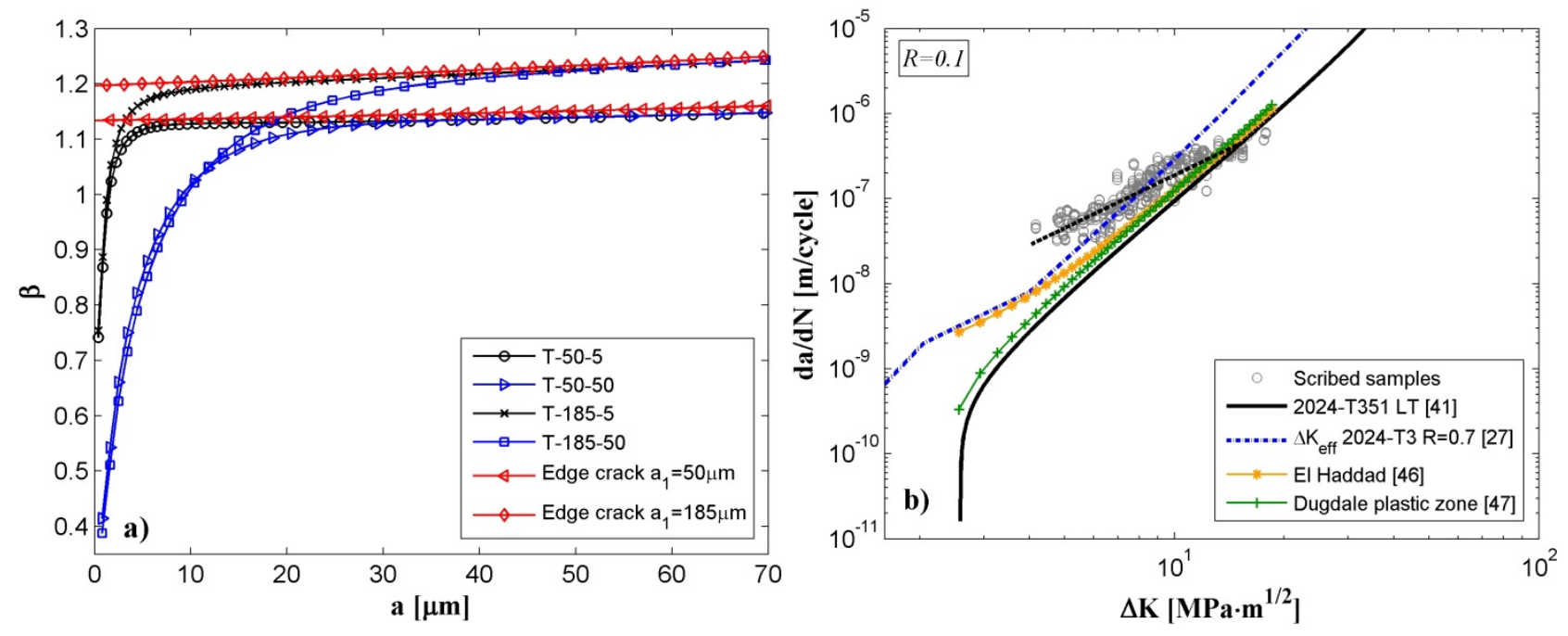
Fig 9

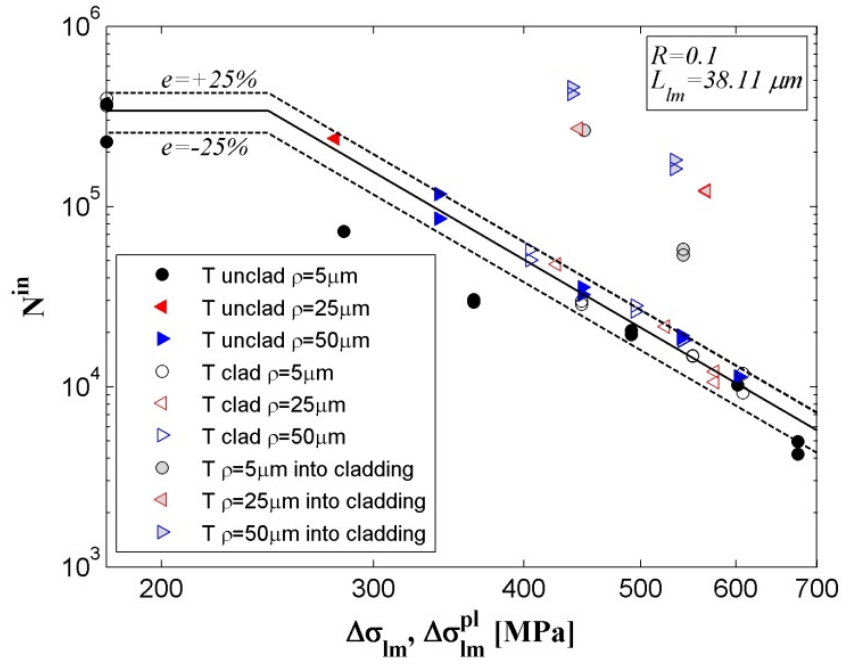




\title{
Development of fatigue cracks from
} mechanically machined scratches on 2024-T351 aluminium alloy - Part II:

\section{finite element analysis and prediction method}

\author{
Cini, Andrea
}

Wiley

Cini, A., and Irving, P. E. (2016) Development of fatigue cracks from mechanically machined pÿscratches on 2024-T351 aluminium alloy Part II: finite element analysis and prediction method. pÿFatigue and Fracture of Engineering Materials and Structures, Volume 40, Issue 6, 2017, pp. 853868 http://dx.doi.org/10.1111/ffe.12545 Downloaded from Cranfield Library Services E-Repository 